\title{
Editorial
}

\section{Special issue on knowledge management for education}

\author{
Kimiz Dalkir \\ School of Information Studies, McGill University, 3661 Peel, Montreal, Quebec, H3A 1X1, Canada \\ E-mail: kimiz.dalkir@mcgill.ca
}

Davenport (1994) defines KM as "the process of capturing, distributing, and effectively using knowledge" (p. 119). As knowledge workers use and learn from this knowledge, both individual and organizational performance and productivity are expected to increase. The challenges are not insignificant and are influenced by a variety of human, cultural, and technological factors. Knowledge management (KM) is an important addition to all information professionals' toolkits, and LIS educators and practitioners recognize the value of KM. For this reason, most KM courses are found in the curricula of Education and Information Science programs. This special issue brings together some of the latest research in the application of knowledge management to problems of higher education. The four papers in this special issue address challenges such as knowledge networks for education and training (communities of practice), KM models for LIS educators, and human, social and technological enablers of knowledge sharing and collaboration.

Denise Bedford surveyed graduate level library and information science programs to look for evidence of the application of the knowledge life cycle. In particular, she investigated the steps of the McElroy Knowledge Life Cycle Model to better understand the processes of learning, unlearning and relearning among faculty as applied to their teaching, research and development responsibilities. This research provides a holistic method of assessing the extent to which LIS schools are learning organizations as they should exhibit these dynamic characteristics of the knowledge lifecycle.

Bilodeau and Carson looked at the learning practices used by academic librarians throughout their careers in order to better understand how LIS schools make use of knowledge networks ("communities of practice") in their professional education. They focused on the self-directed, informal, social interaction and peer networking based learning that helped them learn as they worked as professional librarians. The community of practice model provided the lens through which to study how well their LIS education prepared them to be effective learners.

Bowen and Evans explored the ways in which abstract concepts, in particular the concept of knowledge, could best be communicated through visual means such as drawings. The Englehardt typology of graphical objects was used to categorize how 
participants depicted what they believed knowledge looked like. The use of such drawings may help in teaching and learning the core concepts of Knowledge Management education, which tends to rely on mostly text-based learning materials.

Finally, Jang investigated how students, particularly millennials, collaborate when working on team assignments. In particular, she analyzed how the use of knowledge sharing technologies was related to both learning achievement and the user's learning experience. She developed a pedagogical framework to help educators design effective team-based collaborative learning environments. 